\title{
The effect of anxiety and depression scores of couples who underwent assisted reproductive techniques on the pregnancy outcomes.
}

\author{
Fusun Terzioglu ${ }^{1}$, Rukiye Turk ${ }^{2}$, Cigdem Yucel ${ }^{1}$, Serdar Dilbaz ${ }^{3}$, Ozgur Cinar ${ }^{4}$, Bensu Karahalil ${ }^{5}$
}

1. Hacettepe University, Faculty of Nursing, Ankara, Turkey

2. Kafkas University, Faculty of Health Sciences, Nursing Department, Kars, Turkey

3. Ministery of Health Etlik Zubeyde Hanim Research and Training

Hospital, Ankara, Turkey

4. Ankara University School of Medicine, Department of Histology-Embryology,

Ankara, Turkey

5. Gazi University, Faculty of Pharmacy, Toxicology Department, Ankara, Turkey

\begin{abstract}
Objective: The aim of this study was to determine the effect of anxiety and depression scores of couples who underwent Assisted Reproductive Techniques (ART) on pregnancy outcomes.

Method: This study was conducted as a prospective and comparative study with 217 couples. The study data was collected by using a semi-structured questionnaire and the Turkish version of the State-Trait Anxiety Inventory (STAI), and Beck Depression Inventory (BDI). The questionnaire, STAI and BDI were applied to couples who initiated ART treatment. Couples' state anxiety scores were re-evaluated after embryo transfer (ET).

Results: A significant relationship was found between the depression score of women and pregnancy outcome $(\mathrm{p}<0.05)$. It was determined that anxiety scores for both men and women were higher before the ART procedure, but their anxiety scores decreased after ET $(\mathrm{p}<0.05)$. Spouses of women with a negative pregnancy outcome had higher trait and state anxiety mean scores $(p>0.05)$ and lower depression scores $(p<0.05)$ than spouses of women with a positive pregnancy outcome.

Conclusion: Study results indicated that the anxiety and depression scores of couples who had achieved a positive pregnancy result were lower than for couples with a negative result. The results of this study will contribute to the health professionals especially to the nurses who spend the most time with couples in providing consulting services and supporting psychological status of couples during ART process in Turkey.
\end{abstract}

Keywords: Infertility assisted reproductive techniques, anxiety, depression, pregnancy outcome.

DOI: http://dx.doi.org/10.4314/ahs.v16i2.12

Cite as: Terzioglu F, Turk R, Yucel C, Dilbaz S, Cinar O, Karahalil B. The effect of anxiety and depression scores of couples who underwent assisted reproductive techniques on the pregnancy outcomes. Afri Health Sci 2016;16(2): 441-450. bttp:/ / dx.doi.org/10.4314/ abs.v16i2.12

\section{Introduction}

One of 6 couples attempting to create their own biological family experiences difficulty carrying the pregnancy to term or has other problems during the pregnancy ${ }^{1}$. Infer-
Corresponding author:
Rukiye Turk,
Kafkas University, Faculty of Health Sciences,
Kars, Turkey
Phone (Work): +904742251265
Fax (Work): +904742251265
E-mail: rahsantur@gmail.com

tility affects $10 \%$ to $15 \%$ of the childbearing population in Turkey ${ }^{2}$ and $55 \%$ of those affected will seek medical advice in the hope of becoming parents ${ }^{3}$. When couples cannot fulfill their wish to have a child within a certain time frame, they begin to experience psychosocial, economic, and cultural problems ${ }^{4}$. Infertility is a psychologically threatening, emotionally stressful, economically expensive and often physically painful complex life crisis. Besides, infertility treatment has a known psychological impact on women and their partners ${ }^{5}$.

There is increasing evidence that psychological factors, such as anxiety and depression, are related to ART pro- 
cess and its outcomes ${ }^{4-8}$. Studies have also shown that in couples under stress women may have problems with ovulation induction, missed cycles, a reduction in the rate of pregnancy and a decreased number of oocytes. Males may have decreased sperm parameters in the number, mobility, concentration of sperms and an increase in the morphological deterioration of sperms when compared with obtained data before treatment ${ }^{4,6,8,9}$.

A couple's psychological reaction, such as anxiety and depression, can differ from one another. It is thought that women experience more psychological problems than men because during treatment they must take hormones and undergo so many invasive interventions and procedures. When compared with fertile women, infertile women have a high mean score related to depression, anxiety, hostile behavior and cognitive defect. Psychological stress can reduce women's reproduction performance by affecting the central nervous, endocrine and immune systems $^{10,11}$. Moreover, a reduction in pregnancy ratios has been observed if the stress level is high during a cycle ${ }^{12}$.

Furthermore, if a woman's stress level is high, it can cause a reduction in the number of fertilized oocyte. A study conducted on 818 Danish couples indicated that even a small increase in a woman's level of stress can negatively affect treatment outcome, however, there is no relation between this outcome and an increase in the stress level of men ${ }^{13}$. Another study conducted by Gollenberg et al. ${ }^{12}$ reported that the motility, concentration, and morphology of the sperm of men who experienced 2 or more stressful events ${ }^{12}$ were under the normal limits specified by World Health Organization ${ }^{13}$ when compared to men who had experienced fewer than 2 stressful events ${ }^{13}$. Another study on ART by Dilek et al. ${ }^{14}$ determined that score of state anxiety during the process of ART treatment was within the normal limits and at a similar ratio for both men and women, but women's trait anxiety scores and severity of depressive symptoms were higher than men's ${ }^{14}$. This result verifies the hypothesis that infertile women suffer a heavier emotional burden than their partner.

There are contradictions in the study results related to the effects of depression and anxiety on the process of ART. Thus, the aim of this prospective and comparative study was to determine the effect of anxiety and depression scores of couples who underwent ART on pregnancy outcome.

The study hypotheses were as follows:

H1: Women with high anxiety scores have more negative pregnancy outcome than women with low anxiety scores. H2: Women with low depression scores have more positive pregnancy outcome than women with high anxiety scores.

\section{Materials and method Study design and sample}

This study was conducted as a prospective and comparative study of 217 couples who underwent ART treatment at an in vitro fertilization unit of a state hospital in Ankara. Inclusion criteria were: having marital relationship, not having previous history of live birth, having no psychiatric disease, and being literate.

\section{ART procedure}

Before ART, women's serum levels of hormones such as follicle stimulating hormone, estradiol and luteinizing hormone were evaluated. Transvaginal ultra-sonography and office hysteroscopy were also performed to evaluate uterus, ovaries and cervix. Sperm sample was obtained from men in order to evaluate sperm parameters (count, motility and morphology). Controlled ovarian hyperstimulation involving the use of fertility medications was used to induce ovulation by multiple ovarian follicles. During controlled ovarian hyper stimulation, serial ultrasound monitoring and serum estradiol measurements were performed in order to safely stimulate the ovaries. Oocyte retrieval was performed under general anesthesia using transvaginal ultrasound after obtaining required follicles.

Semen samples were obtained at the time of oocyte retrieval, and sperm motility and morphological assessment were performed. The morphology of oocytes at the time of intra-cytoplasmic sperm injection (ICSI) was evaluated. Oocytes were microinjected by a spermatozoon. At 16-18 h after the ICSI procedure, a fertilization check was performed. Embryos were classified from Grades 1 to 5 (best to worst). Grade 1 or 2 embryos were selected for day 3 or day 5 transfer by the standard procedures in the laboratory. The detailed information about the ART procedure used in this study could be found in another publication $^{15}$. 


\section{Ethical considerations}

Ethical approval to conduct the study was obtained from the University ethics committee and the study hospital's ethics committee. Couples were informed about the study and their written informed consent was taken.

\section{Data collection tools}

\section{Semi structured data collection tool}

This form was developed by the first author of this article $^{4}$. This form was used to determine the characteristics (age, education, marriage history and infertility) of couples and the opinions of the couples about infertility and ART.

\section{Spielberger's State and Trait Anxiety Inventory (STAI)}

The State-Trait Anxiety Inventory (STAI) was developed by Spielberger et al. and adapted for Turkish by Öner and LeCompte $^{16}$. STAI consists of 40 items and includes two separate scales. The "Trait Anxiety Scale" was developed as a means to identify how an individual felt in general. The reliability coefficient determined by the alpha correlation was between 0.83 and 0.87 . The "State Anxiety Scale" is a scale that shows how an individual feels in a situation and in the particular conditions. The reliability coefficient was found between 0.94 and 0.96. Oner and Lecompte defined the normal anxiety level between 36 and 42. Higher scores indicate higher levels of anxiety and the lower scores lower levels of anxiety.

\section{Beck Depression Inventory (BDI)}

Depression scores of couples were evaluated by using Beck Depression Inventory (BDI). BDI consists of 21 items, each corresponding to a specific category of symptoms and attitudes, scored on a range from 0 to 3 . Items include sadness, pessimism, sense of failure, dissatisfaction, guilt, expectation of punishment, self-dislike, self-accusations, suicidal ideas, crying, irritability, social withdrawal, indecisiveness, body image change, work difficulty, insomnia, fatigue, loss of appetite, weight loss, somatic preoccupation, and loss of libido. This inventory had been translated into Turkish by Hisli in $1988^{17}$. Its split-half reliability is $0.74^{18}$ and correlation between MMPI-Depression clinical scale and BDI was 0.63 in the Turkish population ${ }^{17}$.

\section{Data collection}

The study data were collected between January and December 2009. Couples who met the inclusion criteria were asked to fill in a semi structured data collection form at the beginning of the ART treatment. Besides the data collection form, the couples filled out STAI and BDI. The researchers gave information on how to fill out the forms. State Anxiety Inventory was repeated after ET.

\section{Statistical analysis}

The study data was analyzed using Statistical Package for Social Sciences (SPSS) 20.0. In the analysis of the data, percentage, numbers, mean, standard deviation, Pearson's chi-square, Fisher's chi-square, one-way analysis of variance (ANOVA), and independent samples ' $t$ ' test were used. " $p<.05$ " was considered as significant.

\section{Results}

As shown in table 1, the mean trait anxiety score of women was found significantly higher than men $(p<.05)$. However, the mean state anxiety score of men before ART was found higher than women $(\mathrm{p}<.05)$. It was also determined that the mean depression score of women was higher than men $(p<.05)$. In addition, the mean state anxiety score before ART and depression score of nonworking women were clearly higher than the mean score of working women $(p<.05)$. Furthermore, anxiety and depression scores of unemployed women were found to be above the determined threshold value. While there was no statistical difference between infertility duration and mean anxiety and depression scores of couples, we found that women whose perceptions of chance of becoming pregnant were low had higher mean depression score ( $p$ $<.05)$. 
Table 1. Trait-state anxiety and depression mean scores

according to some characteristics.

\begin{tabular}{|c|c|c|c|c|c|}
\hline Characteristics & $\mathbf{n}$ & $\begin{array}{l}\text { Trait Anxiety } \\
\text { Before ART }\end{array}$ & $\begin{array}{l}\text { State Anxiety } \\
\text { Before ART }\end{array}$ & $\begin{array}{c}\text { State Anxiety } \\
\text { After ET }\end{array}$ & Depression \\
\hline \multicolumn{6}{|l|}{ Gender } \\
\hline Women & 217 & $49.60 \pm 6.30$ & $41.96 \pm 5.43$ & $34.79 \pm 8.90$ & $16.35 \pm 10.42$ \\
\hline Men & 217 & $48.12 \pm 7.44$ & $43.43 \pm 6.88$ & $35.72 \pm 8.33$ & $10.95 \pm 8.54$ \\
\hline $\mathbf{t}$ & & -2.469 & 2.248 & $\begin{array}{c}-0.911 \\
\end{array}$ & 5.907 \\
\hline $\mathbf{p}$ & & 0.014 & 0.025 & 0.363 & 0.001 \\
\hline \multicolumn{6}{|c|}{ Working Status of Women } \\
\hline Unemployed & 175 & $42.21 \pm 5.42$ & $50.13 \pm 6.42$ & & $17.28 \pm 10.47$ \\
\hline Employed & 42 & $40.93 \pm 5.41$ & $47.40 \pm 5.29$ & & $12.50 \pm 9.39$ \\
\hline $\mathbf{t}$ & & 1.371 & 2.549 & & 2.707 \\
\hline $\mathbf{p}$ & & 0.172 & 0.011 & & 0.007 \\
\hline \multicolumn{6}{|c|}{ Duration of Infertility (Women) } \\
\hline $0-5$ years & 102 & $49.25 \pm 5.54$ & $41.55 \pm 5.29$ & & $15.07 \pm 10.06$ \\
\hline $6-10$ years & 62 & $49.08 \pm 6.45$ & $42.18 \pm 5.71$ & & $16.68 \pm 10.30$ \\
\hline Over 11 years & 53 & $50.89 \pm 7.36$ & $42.49 \pm 5.40$ & & $18.45 \pm 11.05$ \\
\hline $\mathbf{F}$ & & 1.474 & 0.592 & & 1.894 \\
\hline $\mathbf{p}$ & & 0.231 & 0.554 & & 0.153 \\
\hline \multicolumn{6}{|c|}{ Duration of Infertility (Men) } \\
\hline $0-5$ years & 102 & $47.06 \pm 7,13$ & $42.88 \pm 6,80$ & & $10.53 \pm 8,54$ \\
\hline $6-10$ years & 61 & $48.46 \pm 7,94$ & $44.20 \pm 6,46$ & & $10.34 \pm 8,51$ \\
\hline Over 11 years & 54 & $49.72 \pm 7,23$ & $43.59 \pm 7,51$ & & $12.43 \pm 8,56$ \\
\hline $\mathbf{F}$ & & 2.381 & 0.714 & & 1.084 \\
\hline $\mathbf{p}$ & & 0.095 & 0.491 & & 0.340 \\
\hline \multicolumn{6}{|c|}{ Women's Perceptions of Chance of Becoming Pregnant } \\
\hline Low & 29 & $50.17 \pm 5.26$ & $41.10 \pm 6.25$ & & $22.17 \pm 11.81$ \\
\hline Moderate & 97 & $49.37 \pm 6.35$ & $41.57 \pm 5.10$ & & $15.78 \pm 9.79$ \\
\hline High & 91 & $49.67 \pm 6.59$ & $42.65 \pm 5.48$ & & $15.11 \pm 10.11$ \\
\hline $\mathbf{F}$ & & 0.188 & 1.349 & & 5.531 \\
\hline $\mathbf{p}$ & & 0.829 & 0.262 & & 0.005 \\
\hline
\end{tabular}

Values are shown as mean \pm SD

It was found that there were no statistical differences between state-trait anxiety levels of women and their pregnancy outcomes. However it was determined that the mean depression score for the women whose pregnancy outcome was positive was lower than for the women who had negative pregnancy outcome (figure $1 ; \mathrm{p}<.05$ ). 


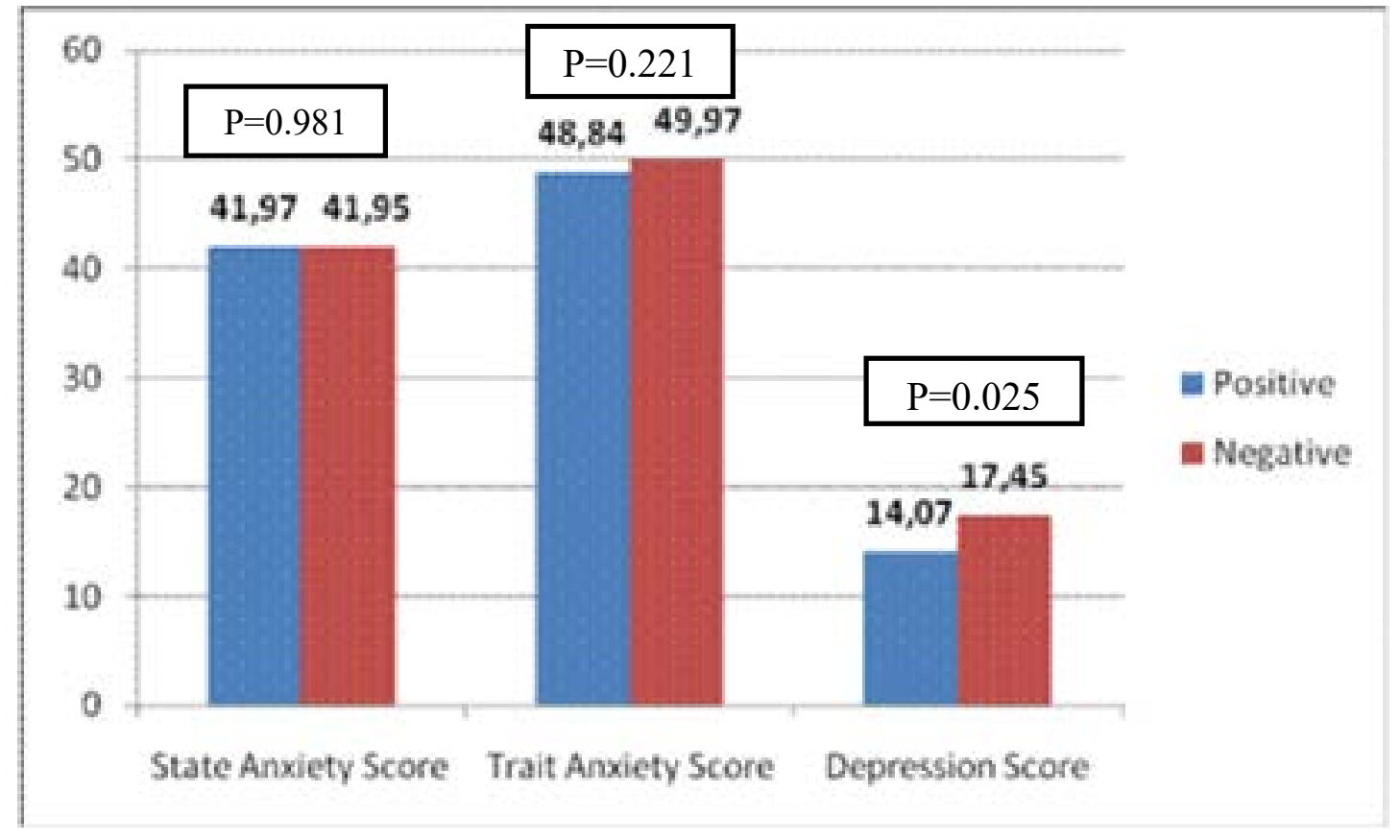

\section{Figure 1. The effect of women's anxiety and depression scores on pregnancy outcome.}

It was found that the mean trait anxiety score of women was clearly higher than the mean state anxiety score before ART (table 2; $\mathrm{p}<.05$ ). It was also determined that the mean state anxiety score of women before ART was clearly higher than the mean state anxiety score after ET (table 2; $\mathrm{p}<.05$ ). Our study results also showed that the mean state anxiety score of men was lower than the mean trait anxiety score (table 2; $\mathrm{p}<.05$ ). Furthermore, the mean state anxiety score of men before ART was clearly higher than their score after ET (table 2; $<$.05).

Table 2. Trait-state anxiety mean scores before ART and after ET according to gender

\begin{tabular}{|c|c|c|c|c|c|}
\hline Gender & Anxiety & $\mathbf{n}$ & $\mathrm{x} \pm \mathbf{S S}$ & $\mathbf{T}$ & $\mathbf{p}$ \\
\hline \multirow{4}{*}{ Women } & State Anxiety Before ART & 217 & $41.96 \pm 5.43$ & \multirow{2}{*}{-16.116} & \multirow{2}{*}{0.001} \\
\hline & Trait Anxiety Before ART & 217 & $49.60 \pm 6.30$ & & \\
\hline & State Anxiety BeforeART & 146 & $42.20 \pm 5.38$ & \multirow{2}{*}{8.045} & \multirow{2}{*}{0.001} \\
\hline & State Anxiety After ET & 146 & $34.79 \pm 8.90$ & & \\
\hline \multirow{4}{*}{ Men } & State Anxiety Before ART & 217 & $43.43 \pm 6.88$ & \multirow{2}{*}{-9.468} & \multirow{2}{*}{0.001} \\
\hline & Trait Anxiety Before ART & 217 & $48.12 \pm 7.44$ & & \\
\hline & State Anxiety BeforeART & 139 & $42.90 \pm 6.40$ & \multirow{2}{*}{7.038} & \multirow{2}{*}{0.001} \\
\hline & State Anxiety After ET & 139 & $35.72 \pm 8.33$ & & \\
\hline
\end{tabular}




\section{Discussion}

Economic, social and physical difficulties and stress experienced by couples during the ART process can affect their psychological status and cause an increase in their anxiety and depression scores. Our study results showed that the mean scores of both state $(x=41.96)$ and trait $(x=49.60)$ anxiety of women before commencing treatment were higher than the mean state anxiety score $(\mathrm{x}=$ 34.79) after ET $(p<.05)$. Another finding concerning the mean anxiety scores of men before ART was that both state $(\mathrm{x}=43.43)$ and trait $(\mathrm{x}=48.12)$ were above threshold value and higher than the state anxiety score $(x=35.72)$ after ET. State anxiety scores obtained after ET indicated normal anxiety level however, the scores of state and trait anxiety before ART indicated high anxiety level. Furthermore, it was determined that the trait anxiety score of women was higher when compared with men (Table 2).

Some studies found the score of state anxiety in women was higher than men ${ }^{4,19-23}$. Another study reported that after ART treatment, the state anxiety of women was negatively affected but there was no change in trait anxiety $^{1}$. Ju su, et al. ${ }^{24}$ determined that women in the group who continued treatment exhibited higher state and trait anxiety than women in the group who discontinued treatment ${ }^{24}$. Both Newton et al. ${ }^{22}$ and Slade et al. ${ }^{25}$ determined that before ART treatment scores of state, trait anxiety and depression for women were significantly higher than for men.

Our study reflected a state of high anxiety in couples before ART due to the uncertainties of the process and outcomes of ART; however, beginning the treatment actually provided a sense of relief to individuals. They also felt more hopeful and this was reflected in a decrease in their state anxiety after ET. In addition, the anxiety scores of couples are fueled by misinformation and superstitions related to infertility, especially ART. For example, some information cites the cause of infertility as due to problems with the woman and not with the man. Other information says the baby born as a result of treatment will be disabled or deformed or that medicines used to treat fertility problems can cause cancer. Such beliefs only serve to increase the anxiety scores of couples undergoing ART. Turkey's social and cultural structure and behav- iors certainly support bringing children into the world. As a result, when couples seek treatment for infertility, the social pressures to bring children into the world can cause an increase in their scores of trait anxiety.

Higher anxiety and depression scores of unemployed women over employed women were determined in this study $(\mathrm{p}<.05)$ (Table 1). Individuals' working status affects both their social and economic life. Women with economic power have much more self-confidence and a sense of control over their lives. Furthermore, in recent decades the status of women in general has been undergoing significant change ${ }^{26}$. Other studies indicate a decrease in infertile women's depression when they have their own profession or work outside the home; our study had the same finding ${ }^{27-29}$. However, another study conducted in 2004 by Oguz found that women's working status had no effect on depression and anxiety scores ${ }^{30}$. Women who worked at home and were therefore responsible for the "domestic economy" of their households were thus distracted in a healthy way from being preoccupied with the treatment process. Adding to their satisfaction was their enjoyment of a supportive social network which kept them busy and connected to others.

The mean state anxiety score of women whose pregnancy outcome was positive was 41.97 while the mean score of women with a negative outcome was 41.95 (p $>$.05) (Figure 1). It was therefore determined that the mean state anxiety score does not statistically affect pregnancy outcome as a result of ART. Karlidere et al.'s study (2008) found that the mean state anxiety score of infertile women was 36.88. This score was also 40.14 for the women with a negative pregnancy result but was lower for women with a positive pregnancy result at 33.21 ( $p$ $<$.01 $)^{31}$. Csemiczky et al.'s study (2000) showed that the anxiety score was high among the women who did not become pregnant ${ }^{20}$. Couples resorting to ART can experience great difficulties both before and during the treatment process. However, infertile couples consider ART as their last chance to have a biological child so they are often prepared to endure many difficulties. In addition, many women are unable to give up their dream of becoming pregnant and having a child. For this reason, a negative outcome can deliver a major disappointment to a couple's hopes for having a child, thus increasing their susceptibility to depression. 
In our study, the mean trait anxiety score of women having a positive pregnancy result $(x=48.84)$ was lower than for women with a negative result $(x=49.97)(p>.05)$; however, for both groups, the mean trait anxiety scores were above normal value, which was a remarkable finding (Figure 1). Karlidere et al.'s study (2008) determined the mean trait anxiety score of infertile women as 47.11. Women with negative pregnancy results were compared with those having positive results, and in terms of the mean trait anxiety score, the first group's score was 49.46 and higher than the second group's score, which was $44.47(\mathrm{p}=.01)^{31}$. In another study conducted in pregnant and non-pregnant women IVF patients found no difference between state and trait anxiety scores ${ }^{32}$.

The social and cultural pressures for women in not being able to fulfill their gender roles by becoming pregnant and giving birth are likely reasons for a high trait anxiety score for both positive and negative pregnancy results. A couple's inability to conceive a biological child may cause various reactions which can include grief at not being able to participate in one of life's most important functions as a mother and father. For many couples there is also the wish and need in wanting to pass on their genes and name to succeeding generations. The physical, mental, and social pressures associated with infertility issues can cause intense feelings of inadequacy and loss of selfconfidence for both men and women, and for these reasons a couple's trait anxiety scores can also be expected to measure above normal limits.

We consider depression score as a crucial variable affecting pregnancy outcome of couples during ART. While a mean depression score for women with a positive pregnancy result was determined as 14.06, the mean depression score for the women with a negative result was determined as 17.45. Moreover, the mean depression score for women with a negative result was found to be significantly higher than women with a positive result $(\mathrm{p}<.05)$ (Figure 1). When some studies have compared women with higher and lower depression scores as related to positive pregnancy results, the higher depression score indicated the lower rate of positive results. Some studies have also found that just after an ART failure, women ${ }^{33}$ and couples ${ }^{24}$ experience some loss of self-confidence. Thus, there was an increase in emotional factors con- cerning depression when compared with before the ART treatment ${ }^{21,33}$. Lintsen et al.'s as study (2009) on anxiety and depression during ART treatment did not find any statistical significance between anxiety-depression score and the pregnancy rate $^{34}$. A finding from a study conducted by Demyttenaere et al.'s study (1998) showed that more symptoms of depression in women indicated a less positive pregnancy rate for those undergoing ART treatment ${ }^{35}$. A study by Hosaka et al. (2003) in Japan reported that the rate of pregnancy rises significantly as depression and anxiety scores of infertile women go down ${ }^{36}$. Similarly, Terzioglu's study (2001) determined that an increase in depression and anxiety scores have negative effects on the process of ART treatment ${ }^{4}$. Excessive stress and anxiety suppress immune functions ${ }^{37}$ and can therefore compromise chances for a successful pregnancy after implantation.

Studies indicate that women show more depressive symptoms than men among infertile couples ${ }^{38,39}$. In our study, the mean depression score of women was found as 16.35 and higher than for men $(\mathrm{x}=10.95)$ (Table $1 ; \mathrm{p}<.05)$. An Iranian study compared 91 infertile couples with 91 fertile couples using BDI found that the depression score of fertile couples $(x=12.68)$ was higher than for infertile couples $(\mathrm{x}=10.63)$. The BDI score for infertile women $(\mathrm{x}=13.89)$ was determined to be higher than for men $(x=11.46)$ (35). Some studies have indicated that for infertile couples, the mean depression score of women was higher than for men ${ }^{21,38,40,41}$. Similarly, many studies have determined that women have high depression and anxiety scores ${ }^{41-47}$.

The literature shows that not being able to conceive and bear a child and the social stigmatization of this increase the anxiety and depression scores of infertile women ${ }^{48}$. At the same time, there are studies indicating no statistically significant difference between infertile and fertile groups in terms of anxiety and depression scores ${ }^{39,49,50}$. Kazandi et al. ${ }^{51}$ found significant differences between the fertile and infertile couples with respect to state and trait anxiety while there were no differences related to depression in both men and women ${ }^{51}$. In Turkey if a woman is unable to bear children, she can be threatened with divorce, the husband's wish to have a second wife, and stigmatization and social exclusion by her husband's family. These factors cancausemoreanxietyanddepression forwomen than men. 
The results of this study indicate that the state anxiety score of men before ART and after ET were higher than women while depression score of women were higher than for men at the beginning of ART. Our study also indicated that the anxiety and depression scores of couples who had achieved a positive pregnancy result were lower than for couples with a negative result. These results are meaningful as they suggest that couples can experience anxiety and depression during ART process. Therefore, the role of health professionals who assist infertile couples in their desire to bear biological children is not only extremely important but also multi-faceted and requires expertise in several disciplines. Nurses are the health professionals who spend the most time with couples in providing consulting services and information to them. A multidisciplinary team approach in which psychologists and psychiatrists are included in all phases of the evaluation and treatment process of infertile couples would provide the most benefits to couples seeking support in their efforts to have their own biological children.

\section{Acknowledgements}

A part of this study was presented at the $14^{\text {th }}$ world congress on controversies in obstetrics, gynecology \& infertility, November 17-20, 2011, Paris, France. This study is a project funded by the Hacettepe university scientific research projects coordination unit (project no: 0801401001(913)). There are two other publications generated from this project. The paper, entitled "does cigarette smoking really have detrimental effects on outcomes of ivf?" Has been published in the European Journal of Obstetrics \& Gynecology and Reproductive Biology (Eur J Obstet Gynecol Reprod Biol 2014, 174, 106-110). The other paper, entitled "The effect of cotinine concentrations in seminal plasma and follicular fluid on the pregnancy outcomes of couples undergoing assisted reproductive techniques" has been accepted for publication and in press in Turkish Journal of Medical Sciences.

\section{Conflict of interest}

The authors have no conflicts of interest to disclose.

\section{References}

1. Demyttenaere K, Nijs P, Evers Kiebooms G, Koninckx PR. Coping and the ineffectiveness of coping influence the outcome of in vitro fertilization through stress responses. Psychoneuroendocrinology 1992; 17 (6): 655- 65.
2. Boivin J, Bunting L, Collins JA, Nygren KG. International estimates of infertility prevalence and treatmentseeking: potential need and demand for infertility medical care. Human Reproduction Update 2007; 22 (10):1506-1512. 3. Bunting L, Boivin J. Decision-making about seeking medical advice in an internet sample of women trying to get pregnant. Human Reproduction Update 2007; 22 (6):1662-8.

4. Terzioğlu F. Investigation into effectiveness of counseling on assisted reproductive techniques in Turkey. $J$ Psychosom Obstetetricse-Gynaecology 2001; 22(3):133-41.

5. Beukers F, Houtzager B.A, Paap MCS, Middelburg KJ, Hadders-Algra M, Bos AF, Kok JH, PGS study group. Parental psychological distress and anxiety after asuccessful IVF/ICSI procedure with and without preimplantation genetic screening: Follow-up of a randomised controlled trial. Early Human Development 2012; 88 (9): 725-30

6. Sohrabvand F, Abedinia N, Pirjani R, Jafarabadi M. Effect of anxiety and depression on ART outcome. Iranian Journal of Reproductive Medicine 2008;6(2):89-94

7. Smeenk JM, Verhaak CM, Eugster A, van Minnen A, Zielhuis GA, Braat DD. The effect of anxiety and depression on the outcome of in-vitro fertilization. Human Reproduction Update 2001;16 (7):1420-423.

8. Boivin J, Griffiths E, Venetis CA. Emotional distress in infertile women and failure of assisted reproductive technologies: Meta-analysis of prospective psychosocial studies. British Medical Journal 2011; 342:48.

9. Terzioglu F. Anxiety of Infertile Men Who Undergo Genetic Testing for Assisted Reproductive Treatment. J Psychosom Obstet Gynaecol 2007;28 (3):147-53.

10. Hjollund NH, Jensen TK, Bonde JP, Henriksen TB, Andersson AM, Kolstad HA, Ernst E, Giwercman A, Skakkebaek NE, Olsen J. Distress and reduced fertility: a follow-up study of first pregnancy planners. Fertility and Sterility 1999;72(1):47-53.

11. Domar AD, Clapp D, Slawsby E, Dusek J, Kessel B, Freizinger M. Impact of group psychological interventions on pregnancy rates in infertile women. Fertility and Sterility 2000; 73(4): 805-11.

12. Gollenberg AL, Liu F, Brazil C, Drobnis EZ, Guzick D, Overstreet JW, Redmon JB, Sparks A, Wang C, Swan $\mathrm{SH}$. Semen quality in fertil men in relation to psychosocial Stress. Fertility and Sterility 2010; 93(4): 1104-111.

13. World Health Organization. WHO laboratory manual for the examination of human semen and sperm-cervical 
mucus interaction. 4th ed. Cambridge, United Kingdom: Cambridge University Press; 1999.

14. Dilek N, Kızılkaya Beji N. Dilek N, Kızılkaya Beji N. Determination of Emotional Reactions of Couples Who Are Treated With Assisted Reproductive Techniques (Dissertation). İstanbul: Haliç University, 2009; 74 p.

15. Cinar O, Dilbaz S, Terzioglu F, Karahalil B, Yücel C, Turk R, et al. "Does Cigarette Smoking Really have Detrimental Effects on Outcomes of IVF?." European Journal of Obstetrics \& Gynecology and Reproductive Biology 2014;174:106-110.

16. Öner N, Le Compte A. State / Trait Anxiety Inventory Handbook (In Turkish), 2nd Edition. Istanbul: Boğaziçi University Press, 1985; 37p.1985; 37p.

17. Hisli N. A Study About Currency Beck'sDepression Inventory. Journal of Psychol 1988;22:118-22.

18. Hisli N. Beck Validity and Reliability for University Students Depression Inventory. Journal of Psychol, 1989;23:3-13.

19. Kee BS, Jung BJ, Lee SH. A study on psychological strain in IVF patients. Journal of Assisted Reproduction and Genetics 2000;17(8): 445-48.

20. Csemiczky G, Landgren BM, Collins A. The influence of stress and state anxiety on the outcome of IVFtreatment: Psychological and endocrinological assessment of Swedish women entering IVF-treatment. Acta Obstetetrica et Gynecologica Scandinavica 2000; 79(2):113-18. 21. Slade P, Emery J, Lieberman BA. A prospective, longitudinal study of emotions and relationships in in-vitro fertilization treatment. Human Reproduction Update 1997; 12(1):183-90.

22. Wright J, Duchesne C, Sabourin S, Bissonnette F, Benoit J, Girard Y.Psychosocial distress and infertility: men and women respond differently. Fertility and Sterility 1991; 55(1):100-8

23. Fassino S, Piero A, Boggio S, Piccioni V, Garzaro L. Anxiety, depression and anger suppression in infertile couples: a controlled study. Human Reproduction Update 2002; 17(11): 2986-94.

24. Juu Su T, Tzeng, YL, Lo SK, Kuo PC. The anxiety of Taiwanese women with or without continuity treatment after previous in vitro fertilisation failure. Journal of Clinical Nursing 2011; 20(15-16):2217-23.

25. Newton CR, Hearn MT, Yuzpe AA. Psychological assessment and follow-up after in vitro fertilization: assessing the impact of failure. Fertility and Sterility 1990; 54(5):879-86.
26. Adak N. Women's Dilemma: Work and Family Life. Journal of Sociology, 2007;142:130-52.

27. Ramezanzadeh F, Aghssa MM, Abedinia N, Zayeri Farid, Khanafshar N, Shariat M, Jafarabadi M. A survey of relationship between anxiety, depression and duration of infertility. BMC Women's Health 2004;9:doi:10.1186/14726874-4.

28. Facchinetti F, Matteo ML, Artini GP, Volpe A, Genazzani AR. An increased vulnerability tostress in associated with poor outcome of in vitro fertilization embryo transfer treatment. Fertility and Sterility 1997; 67(2):309-14.

29. Taymor ML. Emotional aspects of infertility. Fertil Sterility 1982; 37(2):137-45.

30. Oguz D. Effects Of Infertility On Mental Health, Marriage Relationships And Sexual Life Among The Women Undergoing Infertility Treatments] (dissertation). Istanbul: TC. Ministry of Health, Bakırköy Prof. Dr. Mazhar Osman Mental Health and Neurological Diseases Training and Research Hospital, İstanbul, 2004.

31. Karlıdere T, Bozkurt,A., Özmenler,KN, Özşahin A, Küçük T, Yetkin S. The Influence of Emotional Distress on the Outcome of In-Vitro Fertilization (IVF) and/ or Intracytoplasmic Sperm Injection (ICSI) Treatment among Infertile Turkish Women. Israel Journal of Psychiatry \& Related Sciences 2008; 45(1):55-64.

32. Milad MP, Klock SC, Moses S, Chatterton R. Stress and anxiety do not result in pregnancy wastage. Human Reproduction Update 1998;13(8):2296-300.

33. Visser A, Haan G, Wouters I. Psychosocial aspects of in vitro fertilisation. Journal of Psychosomatic Obstetrics and Gynecology 1994; 15(1): 35-45.

34. Lintsen AME, Verhaak CM, Eijkemans MJC, Smeenk JMJ, Braat DDM. Anxiety and depression have no influence on the cancellation and pregnancy rates of a first IVF or ICSI treatment. Human Reproduction Update 2009;24(5):1092-98.

35. Demyttenaere K, Bonte L, Gheldof M, Vervaeke M, Meuleman C, Vanderschuerem D, D'Hooghe T. Coping style and depression level influence outcome in in vitro fertilization. Fertility and Sterility 1998; 69(6): 1026-33.

36. Hosaka T, Matsubayashi H, Sugiyama Y. Effect of a Psychiatric Group Intervention on Emotions, NaturalKiller Cell Activity and Pregnancy Rate in Infertilite Japanase Women. Psychosomatics 2003; 44:134-35.

37. Demyttennaere K, Nijs P, Evers-Kiembooms G, Koninckx PR. Coping, ineffectiveness of coping and the psychoendocrinological stress responses during in vitro 
fertilization. Journal of Psychosomatic Research 1991;35(23):231-43.

38. Algan Ç, Topçuoğlu V. Frequency of Mental Disorders Among Primary Infertile Women Who Assisted Reproductive Techniques And Effects of Infertility on Depression, Anxiety, Anger, Self-Esteem And Quality of Life] (dissertation). Istanbul: Marmara University, 2008; $58 \mathrm{p}$.

39. Güz H, Özkan A, Sarısoy G, Yanık F, Yanık A, Schuiling GA.. Psychiatric symptoms in Turkish infertile women. Journal of Psychosomatic Obstetrics \& Gynecology 2003;24(4): 267-71.

40. Newton CR, Sherrard W, Glavac I. The fertility problem inventory: measuring percieved infertility related stres. Fertility and Sterility 1999; 72(1):54-62.

41. Tüzer V, Tuncel A, Göka S, Doğan Bulut S. Yüksek FV. Atan A, Göka E. Marital adjustment and emotional symptoms in infertile couples: gender differences. Turkish Journal of Medical Sciences 2010; 40(2): 229-37.

42. Domar A, Broome A, Zuttersmeister P. Seibel M, Friedman R. The prevalence and predictability of depression in infertile women. Fertility and Sterility 1992;58(6): 1158-163.

43. Aghanwa, H. Dare FO. Ogunniyi SO. Sociodemographic factors in mental disorders associated with infertility in Nigeria. Journal of Psychosomatic Research 1999; 46(2):117-23.
44. Domar A, Seibel M. Emotional aspects of infertility in infertility a comprehensive text. Edited by: Seibel M. Nerwali CT: Appleton Lange 1990;23-35.

45. Matsubayashi H, Hosaka T, Izumi S, Suzuki T, Makino T. Emotional distress of infertile women in Japan. Hum Reprod 2001;16(5): 966-69.

46. Wischmann T, Stammer H, Scherg H, Gerhard I, Verres R. Psychosocial characteristics ofinfertile couples: a study by the 'Heidelberg Fertility Consultation Service'. Human Reproduction Update 2001;16(8):1753-761.

47. Golombok S. Psychological functioning infertility patients. Human Reproduction Update 1992; 7(2): 2008-212. 48. Fido A, Zahid, MA. Coping with infertility among Kuwaiti women: Cultural perspectives, International Journal of Social Psychiatry 2004;50(4): 294-300.

49. Downey J, Yingling S, McKinney M, Husami N, Jewelewicz R, Maidman J. Mood disorders, psychiatric symptoms, and distress in women presenting for infertility evaluation. Fertility and Sterility 1989; 52(3): 425-32.

50. Berg BJ, Wilson JF. Psychiatric morbidity in the infertile population: a reconceptualization. Fertility and Sterility 1990;53(4): 654-61.

51. Kazandi M, Gunday O, Mermer TK, Erturk N, Ozkinay E. The status of depression and anxiety in infertile Turkish couples. Iranian Journal of Reproductive Medicine 2011;9(2):95-8. 